\title{
Project Manager Motivation: Job Motivators And Maintenance Factors
}

\author{
Tom Henkel, Embry-Riddle Aeronautical University, USA \\ Jim Marion, Embry-Riddle Aeronautical University, USA \\ Debra Bourdeau, Embry-Riddle Aeronautical University, USA
}

\begin{abstract}
The present study explored the applicable motivation factors that contribute to job satisfaction in terms of job motivators and maintenance factors when working on projects. The researchers asked students enrolled in a university advanced project management leadership course to respond to a job motivators and maintenance factors factor selfassessment. This tool is useful in determining the factors that contribute to motivation when working on projects (Lusser \& Achua, 2016). The researchers then conducted a chi-square test to determine whether the observed values were significantly different from an expected value of 18, which is the midpoint. The chi-square goodness of fit test led to the rejection of $\mathrm{H}_{1}$ and the acceptance of $\mathrm{HI}_{\mathrm{a}}$. with a $\mathrm{p}<.001$. Additionally, the chi-square goodness of fit test led to the acceptance of $\mathrm{H}_{2}$ and the rejection of $\mathrm{H}_{2}$. with a $p=.994$. The self-assessment revealed that the students tended to exhibit higher motivator scores and lower maintenance scores. The findings of this study have significant implications for leadership behavior when leading project teams. These findings can also contribute to a better understanding of the motivation factors that characterize team members for the completion of successful projects.
\end{abstract}

Keywords: Project Management; Motivation, Teamwork

\section{INTRODUCTION}

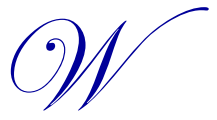
hat motivates project managers and project team members? Is it simply money? Are they motivated by company benefits, status, achievement, affiliation or advancement? These are all good questions for a project manager to answer if he or she is going to be effective in motivating the team members for project success. Project team members' motivation affects productivity, so a large part of a project manager leadership's responsibility is to channel the team towards the successful accomplishment of the project regarding the triple constraints of scope, time, and cost, which should be accomplished in a quality manner (PmBOK, 2013). A project manager may have the necessary technical skills for managing a project; however, throughout the life cycle of a project, he or she is responsible for motivating the project team from project stage to stage for successful project completion (Schmid \& Adams, 2008; Arora \& Baronikian, 2013). Therefore, the question: "What factors motivate project managers and project team members?"

One way in which a project manager can motivate the project team members is by providing several extrinsic rewards, which can include such incentives as outstanding employee awards, bonuses, and merit pay for performance, to name just a few. However, not all project managers have the power to use all of these extrinsic rewards, especially if they are managing projects in a functional or weak matrix organizational structure (Larson \& Gray, 2011). Therefore, it behooves project managers to study the concept of motivation regarding what motivates project team members to initiate action, and what can be done to ensure these team members perform in an outstanding manner, which will lead to superior project completion that satisfies the customer.

In the 1960s, Frederick Herzberg published his popular two-factor theory needs theory. He interviewed hundreds of employees with the question: When were you highly motivated to work, and when were you very dissatisfied and not motivated to work? (Daft, 2014). He combined Maslow's hierarchy lower-level needs into one classification he called hygiene factors (Arora \& Baronikian, 2013). The hygiene factors are also referred to as extrinsic motivators because motivation comes from external sources, specifically from the job itself. External motivators can include working conditions, salary, job stability, a formal title, company policies, and interpersonal relationships (Lussier \& Achua, 
2016). These factors are related to meeting the lower-level needs of Maslow's Hierarchy including physiological needs, safety needs, and self-actualization (Arora \& Baronikian, 2013).

Herzberg (1968) referred to Maslow's hierarchy higher-level needs as classification labeled motivation factors, which also can be referred to as intrinsic motivators and originate within the employee through the work itself (Arora \& Baronikian, 2013). Intrinsic motivators can include accomplishments, recognition, increased responsibility, challenges presented by the work (such as problem-solving), potential for personal growth and even the joy of the work itself (Daft, 2014). These factors are related to meeting Maslow's Hierarchy (1943) higher-level needs of esteem needs and self-actuation and are better suited to motivating employees than extrinsic factors (Arora \& Baronikian, 2013).

Based on their research, Herzberg (1968) and associates differed with the long-held one-dimension model that placed satisfaction and dissatisfaction at opposite ends of one continuum. Instead, they proposed a two-dimensional model that featured two distinct continuums: one that is associated with being not dissatisfied with the environment (maintenance) to be dissatisfied, and one associated with satisfaction with the job itself (motivators) to not being satisfied with the job itself (a two-dimensional model). Herzberg (1968) asserts that organizations that provide maintenance factors can possibly prevent employees from being dissatisfied, but will not achieve the more desirable result of ensuring they are satisfied or motivated by their work.

Under the old management concept, money served as a primary extrinsic motivator and was considered the best stimulus to compel employees to work harder. Money is, in fact, highly important to some and may motivate those employees, but not all employees are motivated simply by pay. Additionally, higher salaries do not necessarily result in harder work. While it is important to pay employees fairly, new leadership paradigms suggest that money is not the most significant motivator for many. Researchers such as Herzberg insisted that maintenance factors, including pay, must first meet to the point that employees are not dissatisfied with these factors (Lussier \& Achua, 2016). Then, employees can be motivated by job enrichment factors that are enmeshed in the job itself. Herzberg (2003) also stressed the importance of making the job more interesting and challenging in order to increase motivation levels.

In a quest to further understand employee motivation, research conducted by Dr. Kenneth Kovach (1999), a professor of management at George Mason University, asked 1,000 employees and 100 of their supervisors to create a list of what that they believed motivates employees. Results showed that the two lists were completely different, with supervisors focusing on extrinsic factors such as salary and job security. Conversely, employees listed intrinsic motivation factors such as finding the work interesting and challenging, feeling appreciated, and being a member of "in groups." The employees did rank extrinsic motivators such as job security and pay as important, but they were lower on the list (Kovach, 1999).

Table 1. Motivating Employees

\begin{tabular}{c|l|c}
\hline Associates' Ranking & \multicolumn{1}{c}{ Items } & Employers' Ranking \\
\hline 1 & Interesting work & 5 \\
\hline 2 & Appreciation of work & 8 \\
\hline 3 & Feeling "in on things" & 2 \\
\hline 4 & Job security & 1 \\
\hline 5 & Good wages & 3 \\
\hline 6 & Promotion/growth & 4 \\
\hline 7 & Good working conditions & 6 \\
\hline 8 & Personal loyalty & 7 \\
\hline 9 & Tactful discipline & 9 \\
\hline
\end{tabular}

Source: Kovach, 1999.

It is interesting to note that after all the motivation research, studies, and discussions by motivation theorists such as Abraham Maslow (1943) and Fredrick Herzberg (1968), the supervisors still rated good wages and security as \#1 and \#2 for employees. It seems that these supervisors were, as McGregor (1960) stated, Theory X managers who believe that "employees seek security above all else" instead of Theory Y managers who believe that "employees' commitment to objectives is a function of the rewards associated with employees' achievement" (Daft, 2014). Most 
managers will argue that wages and security are extremely important, but the employees in the Kovach (1999) study rated interesting work and feeling appreciated as most important. What can be learned from Kovach's study (1999) and analyzing motivation for project managers when leading a team? The hope is to capitalize on information such as the Kovach (1999) research study and assist in answering what factors motivate team members for project success completion. To answer this question, let us first take what employees identified in Kovach's study as being their \# 2 ranking: appreciation of their work (Kovach, 1999). Project managers can encourage team members by showing appreciation and encouragement, both of which come in a variety of forms.

It is important to motivate project team members to superior performance levels, and the higher level of Maslow's Hierarchy labeled motivating factors, which also can be referred to as intrinsic motivators, as components that form within the employee through the work itself. To do so, it is central to first purge any dissatisfaction to then support employees toward attaining contentment. In adhering to Herzberg's theory, the project manager should emphasize motivation (satisfaction) factors such as those that employees rated highly in Kovach's study (interesting work), and concentrate less on hygiene factors (Arora \& Baronikian, 2013). The classical motivation content theorists would add other factors such as authority, responsibility, autonomy, power, and status, along with meaningful and challenging jobs (Daft, 2014). In summary, an essential principle for successfully motivating project team members, is for the project manager show leadership by example and be motivated, committed and enthusiastic about the project and concentrate more on what Herzberg lists as motivating factors and less on hygiene factors (Arora \& Baronikian, 2013).

\section{RESEARCH QUESTION}

The preceding review of motivation research concerning project manager and project team motivation should provide a basis for the factors that motivate project managers and project team members to ensure the success of a project. The current study specifically focuses on the perceptions of students attending an advanced project leadership course regarding motivation in a project setting and attempts to shed light on the following question:

- Do students enrolled in an advanced project management leadership course report job motivators or maintenance factors as their primary motivation when working on projects?

\section{PURPOSE OF THE STUDY}

The purpose of this present research study was to assess the overall alignment of self-assessment survey results of project management students as a means of discovering insight to the factors that motivate them on the job by evaluating survey results.

\section{HYPOTHESES}

H10: Students enrolled in an advanced project management leadership course do not exhibit job motivators as their primary motivator as indicated by their leadership self-assessment scores.

H1a: Students enrolled in an advanced project management leadership course do exhibit job motivators as their primary motivator as indicated by their leadership self-assessment scores.

H20: Students enrolled in an advanced project management leadership course do not exhibit motivation maintenance factors as their primary motivator as indicated by their leadership self-assessment scores.

$\mathbf{H 2}_{\mathrm{a}}$ : Students enrolled in an advanced project management leadership course do exhibit motivation maintenance factors as their primary motivator as indicated by their leadership self-assessment scores

\section{METHODOLOGY}

Therefore, we initiated our consideration of project management students' primary motivation factors with the following research question: 
Do students enrolled in an advanced project management leadership course report job motivators or motivation maintenance factors as their primary motivator when working projects?

- The researchers began their study with a literature review followed by the development of a research hypotheses. After a descriptive analysis, a chi-square analysis was completed and results produced.

\section{DATA COLLECTION}

Students who enrolled in an advanced project management leadership course were requested to complete a job motivators and maintenance factors self-assessment which is a useful framework to determine the factors that contribute to their motivation when working projects. The student responses were tabulated to determine their preferred motivation factors.

\section{Sample Characteristics}

Students working in various industries and organizations internationally and across the United States, including e U.S. military members, responded to the survey; in total, 189 students answered the self-assessment survey. This could be considered a substantial sample of the overall population. The self-assessment consisted of 12 questions about job factors that contribute to job satisfaction (Lussier, \& Achua, 2016). The respondents' privacy and confidentiality were strictly protected.

\section{Analysis of Findings}

The job motivators and maintenance factors style self-Assessment (Lussier, \& Achua, 2016), which is a useful framework for evaluating motivation factors, revealed that the students tended to have higher job motivator scores than maintenance factors scores. As a first step in evaluating the hypotheses, the descriptive statistics of the results of the student assessment were collected and evaluated.

\section{Descriptive Statistics}

From inspection of the descriptive statistics in Table 2, it is evident that the mean is greater than the midpoint (a score of 18 ), and the most common score (mode) was 24.

Table 2. Job Motivators Data Analysis responses

\begin{tabular}{l|r}
\hline \multicolumn{2}{|c}{ Job Motivators } \\
\hline Mean & 25.53 \\
\hline Standard Error & 0.21 \\
\hline Median & 26.00 \\
\hline Mode & 24.00 \\
\hline Standard Deviation & 2.86 \\
\hline Minimum & 3.00 \\
\hline Maximum & 30.00 \\
\hline Count & 187.00 \\
\hline
\end{tabular}

\section{Frequency Analysis-Job Motivators}

The overall distribution of scores is provided in the frequency analysis chart. From inspection, the majority of scores exceeded the midpoint. 
Figure 1. Frequency Analysis-Motivator Ranked Responses

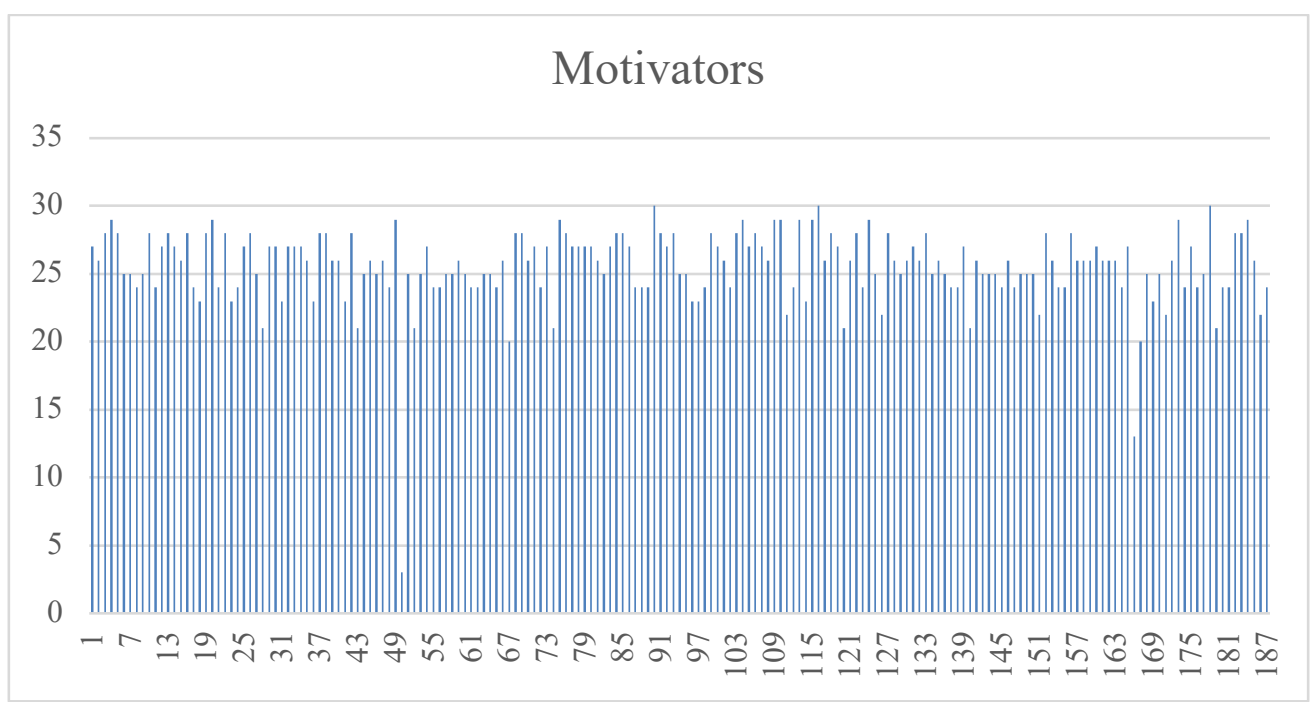

\section{Significance of Job Motivators Scores}

A clear pattern is observed in the descriptive statistics and frequency analysis. Of interest is the degree to which the scores are above the mid-point. The data is presented graphically as follows:

Figure 2. Observed versus Job Motivators Responses

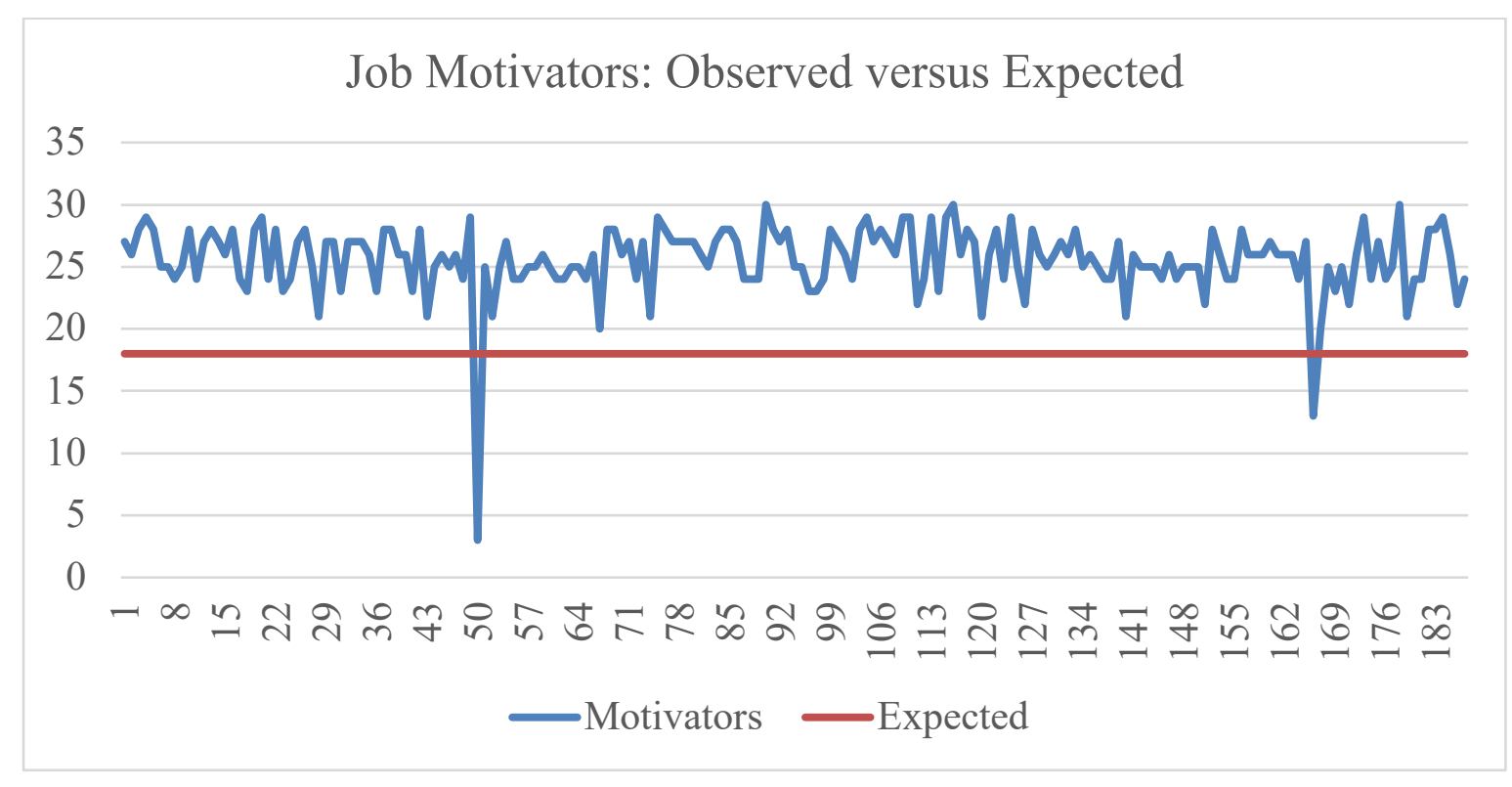

A chi-square test was conducted to determine if the observed values were significantly different from an expected value of 18. The value 18 is the expected value as it is the midpoint of scale from 6 to 30 . The midpoint expected value assumes that the null hypothesis applies and that the student preference selections are therefore randomly distributed. With a p-value $<.001$, the differences were determined to be significant. The chi-square goodness of fit test leads to the rejection of $H 1_{o}$ and the acceptance of $H 1_{a}$ (Minitab, 2013). 
From inspection of the descriptive statistics in Table 2, it is evident that the mean is greater than the midpoint (a score of 18), but the most common score (mode) was 17. The scores lower than the midpoint contributed to the rejection of the null hypothesis as observed in the chi-square goodness of fit test.

Table 3. Maintenance Data Analysis responses

\begin{tabular}{l|r}
\hline & Maintenance Factors \\
Mean & 19.01 \\
\hline Standard Error & 0.25 \\
\hline Median & 19.00 \\
\hline Mode & 17.00 \\
\hline Standard Deviation & 3.39 \\
\hline Minimum & 10.00 \\
\hline Maximum & 30.00 \\
\hline Count & 184.00 \\
\hline
\end{tabular}

\section{Significance of Maintenance Factors Scores}

A clear pattern is observed in the descriptive statistics and frequency analysis. Of interest is the degree to which the scores are above the mid-point. The data is presented graphically as follows:

Figure 3. Observed versus Expected-Maintenance Factors Responses

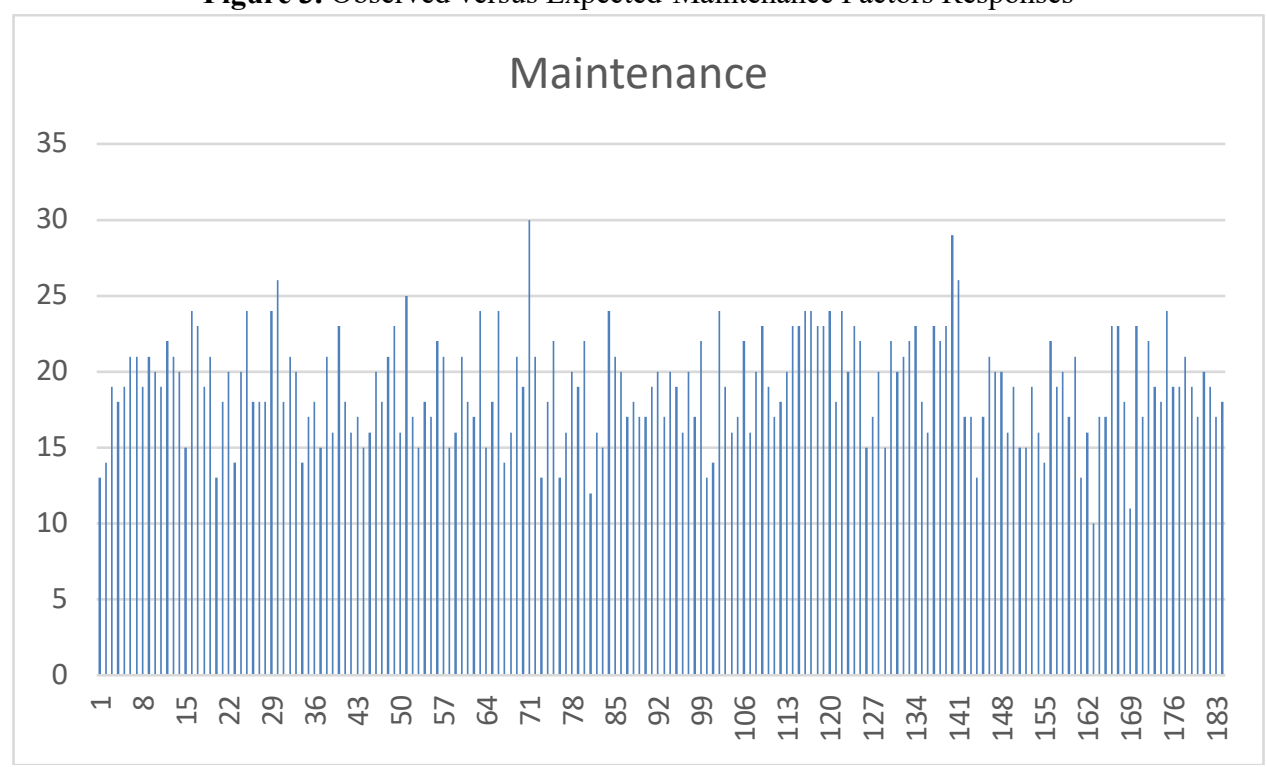

A chi-square test was conducted to determine if the observed values were significantly different from an expected value of 18 The value 18 is the expected value as it is the midpoint of scale from 6 to 30 . The midpoint expected value assumes that the null hypothesis applies and that the student preference selections are therefore randomly distributed. With a $\mathrm{p}$-value $=.994$, the differences were determined to not be significant. The chi-square goodness of fit test leads to the acceptance of $H 2_{0}$ and the rejection of $H 2_{a}$ (Minitab, 2013).

Chi-square: Observed versus expected of 18 (the midpoint of scale from 6 to 30) $\mathrm{P} \leq .994$. Thus, the Maintenance Factors were found NOT to be significant. 
Figure 4. Observed versus Maintenance Factors Responses

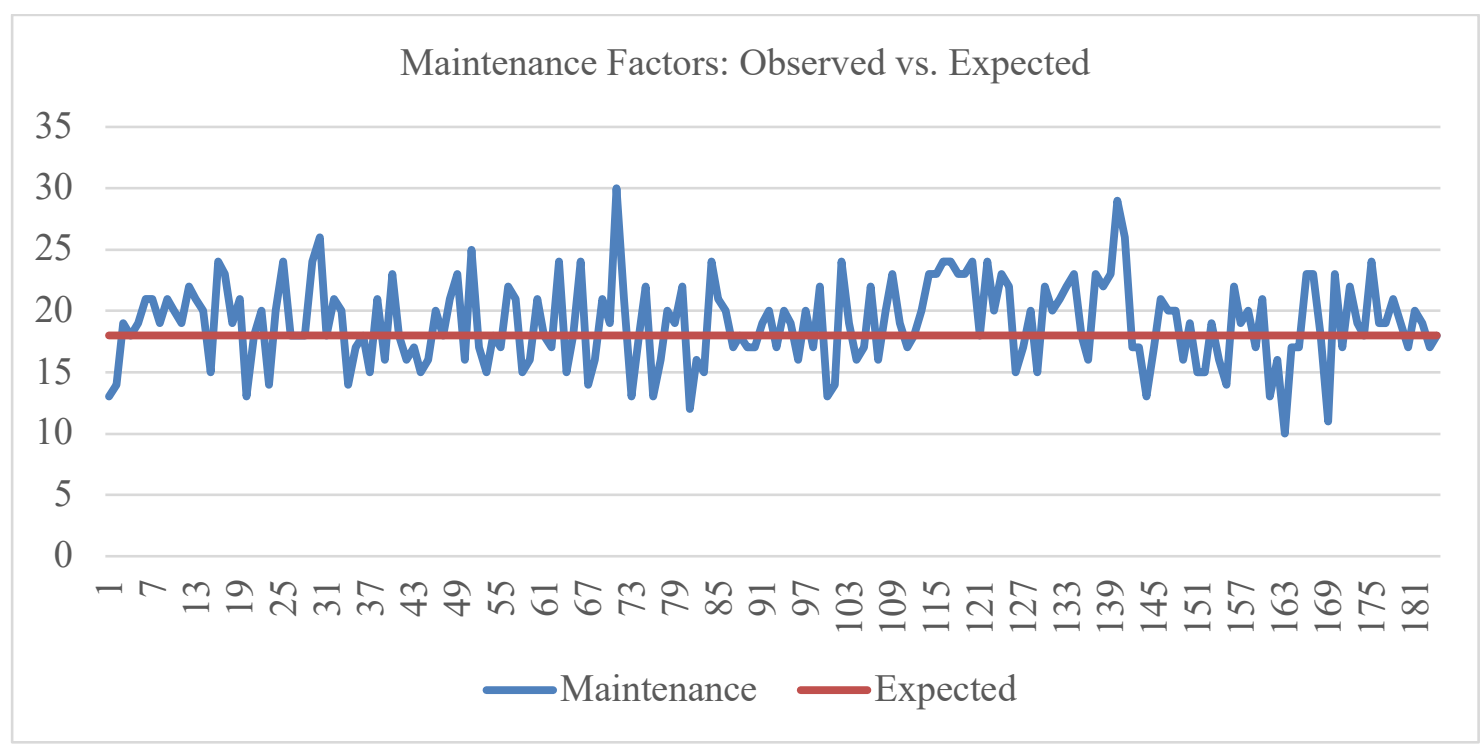

\section{SUMMARY}

The historical development of motivation theory presented provides the formulation of a theoretical perspective for understanding employee motivation as presented by Abraham Maslow's hierarchy of needs theory (1943) and Frederick Herzberg's two-factor theory (1968). These content theories attempted to explain why humans are motivated in their work, and also propose applying reinforcement for shaping and motivating human behavior (Schermerhorn, Hunt, \& Osborn, 2010). Moreover, these content theories are designed around the concepts of providing extrinsic and intrinsic rewards as incentives for creating a motivating work environment. Project managers can influence project team members' motivation behavior by creating a work environment in which appropriate extrinsic are presented, but their aim should be providing the intrinsic motivation factors that will be most beneficial because the team members will be connected to the cause or goal of the project, instead of the rewards that are attached to it (Schmid \& Adams, 2008). Therefore, it is vital that a project manager be skilled in the interpersonal skills of leading and realize the factors associated with motivating themselves and the project team members to successful project completion (PmBOK, 2013).

The goal of this present research study was to assess the overall alignment of self-assessment survey results of project management students as a means of discovering insight into the factors that motivate them and project team members on the job by evaluating survey results. It is hoped that the findings of this study provided insight in to the factors that motivate project managers and project team members when working on assigned projects. The research revealed that the students tend to exhibit higher motivator scores and lower maintenance scores. The findings of this study have significant implications for the success of project managers when leading project teams.

\section{AUTHOR BIOGRAPHIES}

Dr. Tom Henkel, PMP is an Associate Professor in the Department of Leadership and Management at Embry-Riddle Aeronautical University. His research interests include leadership, management, and project management. Dr. Henkel earned his doctorate in Adult Leadership from Auburn University and his doctorate in Business Administration from Northcentral University. E-mail: Thomas.henkel@erau.edu

Dr. Jim Marion, PMP is an Associate Professor in the Department of Decision Sciences at Embry-Riddle Aeronautical University. His research interests include project management, change management, and engineering management. He has a Ph.D. in Organization and Management with a specialization in Information Technology Management from Capella University. E-mail: marionj@erau.edu 
Dr. Debra Bourdeau has a PhD in English from the University of Georgia. She is currently the Chair of the Department of English, Humanities and Communication at Embry-Riddle Aeronautical University Worldwide. Her research interests include interdisciplinary humanities, specifically the exploration of STEM field through the lens of humanities disciplines. She earned a Ph.D. in English from the University of Georgia. E-mail: Taylo13f@erau.edu

\section{REFERENCES}

Arora, M. \& Baronikian, H. (2013). Leadership in project management ( $2^{\text {nd }}$ ed). Canada: Leadership Publishing House. Daft, R. (2014). The leadership experience ( $6^{\text {th }}$ ed.). Canada: Thomson/South-Western.

Herzberg, F. (1968, January-February). How do you motivate employees? Harvard Business Review, 53-62.

Herzberg, F. (2003, January). One more time: How do you motivate employees? Harvard Business Review. Retrieved from https://hbr.org/2003/01/one-more-time-how-do-you-motivate-employees/ar/1

Kovach, K. (1999). Employee motivation: Addressing a crucial factor in your organization's performance, School of Business Administration, George Mason University.

Larson, E, \& Gray, C. (2011). Project management: The managerial process. (6th ed.). Mc-Graw-Hill Education: New York, NY.

Lussier, R. \& Achua, C. (2016). Leadership: Theory, application, \& skill development. (6 ${ }^{\text {th }}$ ed.). South-Western: Mason, OH.

Maslow, A. (1943). A theory of motivation. Physiological Review, 50, 370 - 396.

McGregor, D. (1960). The human side of the enterprise. McGraw-Hill, New York, NY.

Minitab.(2013). Minitab statistical software. Retrieved from http://www.minitab.com/en-us/products/minitab/

PMBOK Guide (2013). A guide to the project management body of knowledge (5th ed.). Newtown Square, PA: Project Management Institute.

Schermerhorn, J., Hunt, J. \& Osborn, R., (2010). Organizational behavior (11 ${ }^{\text {th }}$ ed.). John Wiley \& Sons, Inc. New York, NY. Schmid, B. \& Adams, J. (2008). Motivation in project management: The project manager's perspective. Project Management Journal, 39(2), 60-71. 